Article

\title{
Comparison of Structured Nutrition Therapy for Ramadan with Standard Care in Type 2 Diabetes Patients
}

\author{
Barakatun-Nisak Mohd Yusof ${ }^{1,2, *}$, Wan Zul Haikal Hafiz Wan Zukiman ${ }^{3}$, Zalina Abu Zaid ${ }^{1}$, \\ Noraida Omar ${ }^{1}$, Firdaus Mukhtar ${ }^{2,4}$, Nor Farahain Yahya ${ }^{1}$, Aainaa Syarfa Mohd Shahar ${ }^{1}$, \\ Farah Yasmin Hasbullah ${ }^{1}$, Rachel Liu Xin Yi ${ }^{5}$, Agnieszka Marczewska ${ }^{6}$ and Osama Hamdy ${ }^{7}$ \\ 1 Department of Nutrition \& Dietetics, Faculty of Medicine \& Health Sciences, Universiti Putra Malaysia, \\ Serdang 43400, Selangor, Malaysia; zalina@upm.edu.my (Z.A.Z.); noraidaomar@upm.edu.my (N.O.); \\ farahainyahya93@gmail.com (N.F.Y.); ainasyarfa@gmail.com (A.S.M.S.); farahyasmin90@gmail.com (F.Y.H.) \\ 2 Institute for Social Science Studies, Universiti Putra Malaysia, Serdang 43400, Selangor, Malaysia; \\ drfirdaus@upm.edu.my \\ 3 Department of Medicine, Faculty of Medicine \& Health Sciences, Universiti Putra Malaysia, Serdang 43400, \\ Selangor, Malaysia; zulhaikal@upm.edu.my \\ 4 Department of Psychiatry, Faculty of Medicine \& Health Sciences, Universiti Putra Malaysia, Serdang 43400, \\ Selangor, Malaysia \\ 5 Nestlé Health Science, Petaling Jaya 47810, Malaysia; Rachel.LiuXinYi@my.nestle.com \\ 6 Nestlé Health Science, 1800 Vevey, Switzerland; Agnieszka.Marczewska@nestle.com \\ 7 Joslin Diabetes Centre, Harvard Medical School, MA 02215, USA; Osama.Hamdy@joslin.harvard.edu \\ * Correspondence: bnisak@upm.edu.my
}

Received: 11 February 2020; Accepted: 17 March 2020; Published: 19 March 2020

check for updates

\begin{abstract}
Background: Structured nutrition therapy (NT) is essential for the management of type 2 diabetes (T2D), but the optimal delivery during Ramadan fasting remains unclear. The present study aimed to evaluate the effect of structured NT program versus standard care in patients with T2D during Ramadan. (2) Methods: The present study was an 8-week, parallel, non-randomized study with patients' preference design involving 64 patients with T2D. The participants were asked to choose their preferred group, i.e., structured NT (Structured Ramadan NT, sRNT) or standard care (SC). The participants in the sRNT group received a Ramadan-focused nutrition plan, including a diabetes-specific formula throughout the study, whereas the patients in the SC group received standard nutrition care. Study outcomes included clinical outcomes and quality of life (QoL). Data was analyzed using two-way repeated-measures ANOVA and linear mixed-effects model. (3) Results: More than half of the participants $(n=38,63 \%)$ chose sRNT as their preferred group. Both groups had comparable baseline characteristics. After 8-weeks of the respective intervention, participants in the sRNT group had lower levels of fasting plasma glucose $(-0.9 \pm 0.3 \mathrm{mmol} / \mathrm{L} \mathrm{vs.} 0.2 \pm 0.3 \mathrm{mmol} / \mathrm{L}$, $p<0.05)$, triglycerides $(-0.21 \pm 0.08 \mathrm{mmol} / \mathrm{L}$ vs. $0.20 \pm 0.17 \mathrm{mmol} / \mathrm{L}, p<0.05)$, and self-monitoring glucose at pre-dawn $(6.9 \mathrm{mmol} / \mathrm{L}$ vs. $7.8 \mathrm{mmol} / \mathrm{L}, p<0.05)$ and pre-bedtime $(7.6 \mathrm{mmol} / \mathrm{L} \mathrm{vs} .8 .6 \mathrm{mmol} / \mathrm{L}$, $p<0.05)$ than participants in the SC group. Although not different between groups, HbA1c levels decreased significantly in the sRNT $(-0.72 \pm 0.16 \%, p<0.001)$ but not in the SC group $(-0.35 \pm 0.24 \%$, $p=0.155)$. QoL and satisfaction scores improved significantly in sRNT group, but not in SC group. (4) Conclusions: The structured NT regimen for Ramadan is a feasible and beneficial program for T2D patients observing Ramadan fasting as it showed an improvement in clinical outcomes and QoL.
\end{abstract}

Keywords: structured nutrition therapy; Ramadan nutrition plan; type 2 diabetes; diabetes-specific formula; HbA1c; fasting 


\section{Introduction}

Daytime fasting during the Ramadan month is an important religious practice in Islam. During the entire month of Ramadan, all healthy Muslims fast every day from dawn to sunset with fasting hours across the world varying between 11 and 22 hours, depending on the latitude. In Southeast Asia, including Malaysia, the average fasting period lasts about 14 hours. During the daytime in Ramadan, people abstain from any food or beverage, including water. The daily diet consists of two main meals named as Suhoor, consumed before dawn, and Iftar, consumed after sunset. The daily Ramadan routine causes a sudden change in meal and sleep patterns, which increases the risk of nutritional issues [1].

The shift in eating patterns has significant implications for the physiology process, in particular to people with diabetes. When fasting, insulin resistance or deficiency state can cause excessive glycogen breakdown leading to gluconeogenesis. The alteration put individuals with diabetes at an increased risk to develop hypoglycemia, hyperglycemia, ketoacidosis, and dehydration [2]. Therefore, they are exempted from fasting, but many Muslim adults with diabetes continue to observe Ramadan fasting, even against medical advice. The CREED study documented that $94 \%$ of patients with type 2 diabetes (T2D) fasted for at least 15 days during Ramadan, with more than half (64\%) fasting every day [3]. Nonetheless, with proper Ramadan-focused education, medical risk, including hypoglycemia, can be minimized [4].

In diabetes, changes in timing and meal composition have a considerable impact on glycemic control [5]. Long hours of abstaining from foods during the daytime may lead to excessive food consumption at night, comprising vast amounts of food rich in carbohydrates. The International Diabetes Federation and the Diabetes and Ramadan International Alliance have recently published the guideline for Ramadan Nutrition Plan (RNP) [6]. No study has determined the feasibility of RNP in the real clinical scenario; therefore, further investigation to elucidate the effects of RNP is warranted. The effects of structured nutrition therapy (NT), including the use of diabetes-specific formula (DSF) to facilitate weight management and glycemic control in T2D, have been well established [7-9], but these studies have been performed outside the Ramadan period. The optimal administration of structured NT regimen during Ramadan fasting remains unclear. Many studies have reported the benefits of providing Ramadan-focused intervention [4,10-14]. Nonetheless, none of these studies have explored the potential of structured NT, including the use of DSF in patients' diets during Ramadan fasting. The best criterion for inclusion of DSF during Ramadan is uncertain. Therefore, the present study aimed to evaluate the effect of structured NT versus standard care during Ramadan fasting on clinical parameters and quality of life (QoL) in patients with T2D.

\section{Materials and Methods}

\subsection{Study Population}

Muslim patients aged 18-65 years, who had a confirmed diagnosis of T2D for at least 3 months and expressed their intention to fast for at least 15 days during Ramadan, were recruited in the study. They were not on insulin therapy and treated with a stable dose of other diabetes medications for $>2$ months before enrolment. They had their $\mathrm{HbA} 1 \mathrm{c}$ level between $6.5 \%$ and $12.0 \%$, and body mass index (BMI) between 18.5 to $40.0 \mathrm{~kg} / \mathrm{m}^{2}$. They were also adults who were able to perform activities of daily living (ADLs) independently, such as cooking and preparing meals themselves. The following patients were excluded from the study: pregnant or breastfeeding women, patients with a history of hypoglycemia leading to hospitalization during the previous Ramadan fasting, and the patients who were actively enrolled in weight management programs. Study participants were the patients who visited the Universiti Putra Malaysia Health Centre for their routine diabetes treatment and were recruited through advertisement and clinic referrals. After screening, eligible participants signed the study consent form. The Institutional Review Board approved the study (reference number JKEUPM-2019-009) with the trial registration at clinicaltrials.gov (identifier: NCT03817099) and Malaysia National Medical Research Register (registration number 45868). 


\subsection{Study Design}

The present study was an 8-week, parallel-group, non-randomized study conducted between April 2019 and July 2019. The design considered patients' preference for the allocation to a study arm. Eligible participants chose their preferred group, i.e., structured NT (structured Ramadan Nutrition Therapy, sRNT) or standard care group (SC). The primary outcomes included patients' preference for the study groups, and glycemic parameters, including fasting plasma glucose, $\mathrm{HbA} 1 \mathrm{c}$, and self-monitoring blood glucose profiles. Secondary outcomes included changes in body weight, cardiovascular risk factors, dietary intake, and QoL. A sub-sample of the participants $(n=21)$ were invited to participate in the continuous glucose monitoring (CGM) study to evaluate the glucose profiles during Ramadan fasting further.

\subsection{Study Procedures}

\subsubsection{Structured Ramadan Nutrition Therapy Group}

Participants in the sRNT group received the RNP according to the International Diabetes Federation and the Diabetes and Ramadan International Alliance guidelines [6], including the use of DSF after consulting a research dietician. Participants visited the health clinic four times: at baseline (1-2 weeks before Ramadan), pre-Ramadan, end-Ramadan, and post-Ramadan (2-3 weeks after end-Ramadan) for a total period of 8 weeks (Figure 1). The meal plans aimed to meet daily caloric targets either for weight reduction or maintenance. A dietary plan for a reduced caloric intake of 1200-1500 kcal/day for women and 1500-1800 kcal/day for men was designed and distributed between the two main meals: Suhoor (pre-dawn meal) and Iftar (sunset meal), and two snacks (if necessary) (Table S1). In particular, dietary carbohydrates ( $50 \%$ of total energy intake (TEI)) were distributed accordingly among the four mealtimes (Table S2).

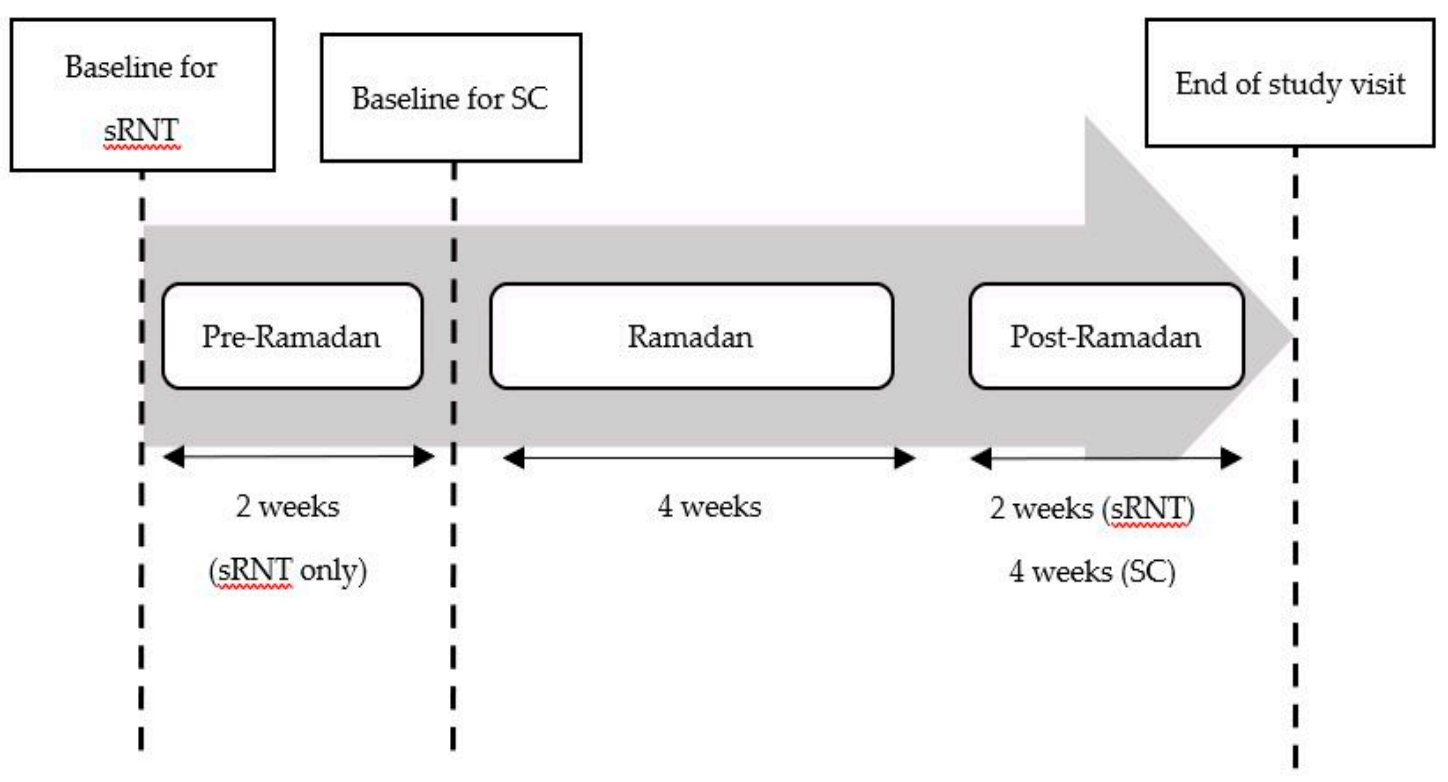

Figure 1. Study design.

The structured NT recommends the use of DSF within participants' caloric and carbohydrate limits [9]. Unlike other studies, where the DSF has been used as a meal replacement [7-9], our study incorporated at least one serving of the DSF (Nutren Untuk Diabetik ${ }^{\circledR}$, Nestlé Health Science, Switzerland) per day during Ramadan and to be consumed together with other foods at Suhoor (pre-dawn meal) and/or at a pre-bed snack (Snack 2) within caloric and carbohydrate limits. The DSF provides approximately $250 \mathrm{kcal}$ per serving with balanced macronutrients composition. The 
DSF contains prebiotics, is rich in dietary fibre, high in whey protein, and low in glycemic index (GI) (Nutren Untuk Diabetik ${ }^{\circledR}$, Nestlé Health Science, Switzerland).

Participants received a structured RNP using a specific Ramadan toolkit consisting of a flip chart on Ramadan-focused education and construction of the balanced meal plan for Ramadan. They were provided with a 14-day meal plan based on the Malaysian diet (Table S3) and Ramadan nutrition plate (Table S4). With this plate, participants were taught the portion size using hand jive [15] and the meal order method of eating vegetables before carbohydrates [16]. During the study, nutritional issues were discussed and addressed by a research dietician via social networking applications. In the final week of Ramadan, participants also received a nutrition plan for the festive season (Syawal nutrition plan). Table 1 summarizes the nutrition strategies in sRNT.

Table 1. A summary of nutrition strategies in structured Ramadan Nutrition Plan and Standard Care.

\begin{tabular}{|c|c|}
\hline Structured Ramadan Nutrition Therapy (sRNT) & Standard Care (SC) \\
\hline $\begin{array}{l}\text { Received structured Ramadan Nutrition Plan consisting of; } \\
\text { - } \quad \text { pre-Ramadan nutrition education } \\
\text { individualized energy and macronutrient prescriptions } \\
\text { for Ramadan fasting } \\
\text { - consumption of diabetes-specific formula of at least } 1 \\
\text { serving/day during Suhoor and/or pre-bed snack. } \\
\text { the Ramadan toolkits (Ramadan flip chart, 14-day menu } \\
\text { plan, Ramadan Nutrition Plate, and Festive season } \\
\text { nutrition plan (Syawal nutrition plan). }\end{array}$ & $\begin{array}{l}\text { Continued usual treatment consisting of; } \\
-\quad \text { standard nutrition care recommendations [17] } \\
\text { - } \quad \text { individualized modification of usual food intake } \\
\quad \text { suit Ramadan fasting } \\
\text { - The Healthy Malaysian plate [18] }\end{array}$ \\
\hline
\end{tabular}

\subsubsection{Standard Care Group}

Participants in the SC group visited the health clinic three times, i.e., at baseline, end-Ramadan, and post-Ramadan during the 8 weeks study period (Figure 1). The patients in the SC group continued to follow the standard of nutrition care recommendations (Table 1) [17]. The participants' usual intake was modified by a research dietician to suit Ramadan fasting. The portion size of the meals was demonstrated using a Healthy Malaysian plate [18]. This method teaches the individual to plan meals such that half of their plate is filled with non-starchy vegetables, and the remainder of the plate is divided between lean protein and carbohydrate. During the study, nutritional issues were discussed and addressed within the frame of standard nutrition care.

\subsection{Outcome Measurements}

Participants' preferences for each study group were assessed at the end of the study. Other feasibility outcomes were measured at three time points in both groups, i.e., at baseline, end-Ramadan, and post-Ramadan during a total study duration of 8 weeks. Anthropometry measurements, blood pressure, and blood samples were assessed at each visit. Body weight was measured using a calibrated scale (TANITA HD-319, Tanita Corporation, Tokyo, Japan), height was measured using a stadiometer (SECA, Hamburg, Germany), and patients' body mass index (BMI) was calculated. Waist circumference was measured at the midpoint between the lower margin of the palpable rib and the top of the iliac crest with a non-elastic measuring tape (SECA 201, SECA, Hamburg, Germany).

Seated blood pressure was measured twice using an automated device (OMRON HEM-7120, Omron, Kyoto, Japan) after a 5 min rest. Before Ramadan, blood was withdrawn after an overnight fast of $10 \mathrm{~h}$, while during Ramadan, blood was taken $10 \mathrm{~h}$ after Suhoor and was analyzed using an automated system in an established laboratory (B.P. Clinical Lab Sdn Bhd, Shah Alam, Malaysia). Blood measurements included the estimation of levels of $\mathrm{HbA1c}$, fasting blood glucose, and lipid profile.

Dietary intake and macronutrients were assessed using 3-day food records. Participants were taught, and written instructions were given for recording the food intake. The research dietician reviewed food records at each visit. The average of 3-day food intake data was analyzed for daily total energy intake (TEI), the proportion of macronutrient composition from TEI (\%TEI), total fiber and selected micronutrient intake using the Nutritionist Pro software (V.5.1.0, Axxya Systems, WA, 
USA). The reliability of food intake data was ensured by including only those with plausible energy intake of 400-3500 kcal/day for women, and 700-4000 kcal/day for men [19,20]. The assessment of under-reporting of energy intake was performed at baseline using the Goldberg method [21].

QoL was measured at baseline and post-Ramadan visits using the Malay version of the Revised version of Diabetes Quality of Life (RV-DQOL13) questionnaire for adult population with Type 2 Diabetes Mellitus [22]. The RV-DQOL13 consists of 13 items, measuring three domains: (i) satisfaction, (ii) impact, and (iii) worry. Reliability was confirmed with the Cronbach's alpha coefficients of 0.846 and 0.941 for total and the three domains, respectively [22].

All participants were requested to record a daily finger-pricked capillary self-monitoring blood glucose (SMBG) level using provided glucometer (Contour Plus One, Ascensia Diabetes Care, Basel, Switzerland) at five-time points throughout the study period. During the non-Ramadan period, the time points of daily assessments were at fasting (between 5 and $7 \mathrm{am}$ ), 2-h post-breakfast (between 7 and $9 \mathrm{am}$ ), pre-lunch (between $11 \mathrm{am}$ and $1 \mathrm{pm}$ ), pre-dinner (between 6 and $8 \mathrm{pm}$ ), and pre-bed (between 10 and $11 \mathrm{pm}$ ). During Ramadan, daily blood glucose was monitored at pre-dawn (between 4 and $5 \mathrm{am}$ ), 2-h post-dawn meal (between 6 and $7 \mathrm{am}$ ), at midday (between 12 noon and $1 \mathrm{pm}$ ), pre-Iftar (between 6 and $7 \mathrm{pm}$ ) and pre-bed (between 10 and $11 \mathrm{pm}$ ).

To further understand the glucose profiles during Ramadan fasting, a sub-sample of the participants $(n=21)$ volunteered to join the CGM (Medtronic Minimed ${ }^{\circledR}$, Northridge, CA, USA) study. CGM sensor was inserted into the fatty areas of the abdomen or gluteus (approximately 2 inches above the navel or below the waistline) while avoiding areas where the body naturally bends. For validity purposes, participants performed finger prick calibrations using the glucometer up to five times a day. After 5 days, the sensor was removed, and data was downloaded to a given software (Medtronic CareLink iPro, Northridge, CA, USA). The outcome measures included average sensor glucose, estimated $\mathrm{HbA1c}$, percentage of time-within-target $(3.9-8.3 \mathrm{mmol} / \mathrm{L})$, time-below-target $(<3.9 \mathrm{mmol} / \mathrm{L})$, and time-above-target $(>8.3 \mathrm{mmol} / \mathrm{L})$ glucose ranges per day [23].

\subsection{Sample Size}

A total of 70 participants was sufficient to detect a mean difference of $0.84 \%$ in $\mathrm{HbA} 1 \mathrm{c}$ level among T2DM patients after following a telemonitoring intervention during Ramadan with $80 \%$ power and $90 \%$ confidence interval [24]. A total of 84 participants would be needed in the study after considering a dropout rate of $20 \%$. In this feasibility study, we recruited at least $70 \%$ of participants from the primary planned statistical analyses [25]. Hence, a minimum of 59 subjects were required for this study.

\subsection{Statistical Analyses}

Statistical analysis was performed using the latest SPSS version for Windows (IBM Corp, Armonk, NY, USA; 2013); $p$-value $<0.05$ was considered as statistically significant. Data are expressed as mean \pm standard deviation (SD) for continuous parameters and percentages for categorical parameters. The normality of the data was confirmed using the Shapiro-Wilk test. Baseline characteristics of the two groups were compared using an independent t-test for continuous variables and Pearson's chi-squared test for categorical variables. The changes over time were analyzed using a two-way repeated-measures ANOVA considering the effect of time, group, and the interaction effects (intervention effects) as the main study outcomes. The primary analysis was intention-to-treat (ITT) as it provides an unbiased estimate of treatment effect [26]. Using the ITT, all participants were included in the analysis regardless of drop-out and adherence to study protocol. Imputation of missing data using the last observation carried forward produced no effect on the significance in per-protocol (PP) analysis. Hence, we present the results for the planned ITT analysis. The SMBG data were analyzed using the linear mixed-effects model, which provides a flexible, likelihood-based approach to treat missing data and within-subject correlation. For CGM data, ANOVA was used for analysis after adjusting for the baseline value. 


\section{Results}

\subsection{Recruitment and Baseline Characteristics}

We identified 138 individuals for eligibility, among whom 64 agreed to participate in the study (Figure 2). In total, 60 participants completed the study (6\% attrition rate) with more than half $(n=38$, $63 \%$ ) of the participants choosing the sRNT regimen, and the remaining $(n=22 ; 37 \%)$ continuing to receive the standard care (SC group, Figure 2). The dropout rate was comparable between the two groups. The leading causes of dropout included time constraints and uncontactable for education. Three participants in the sRNT group declined to participate before receiving the intervention, and one participant from the SC group dropped out during Ramadan's visit (Figure 2).

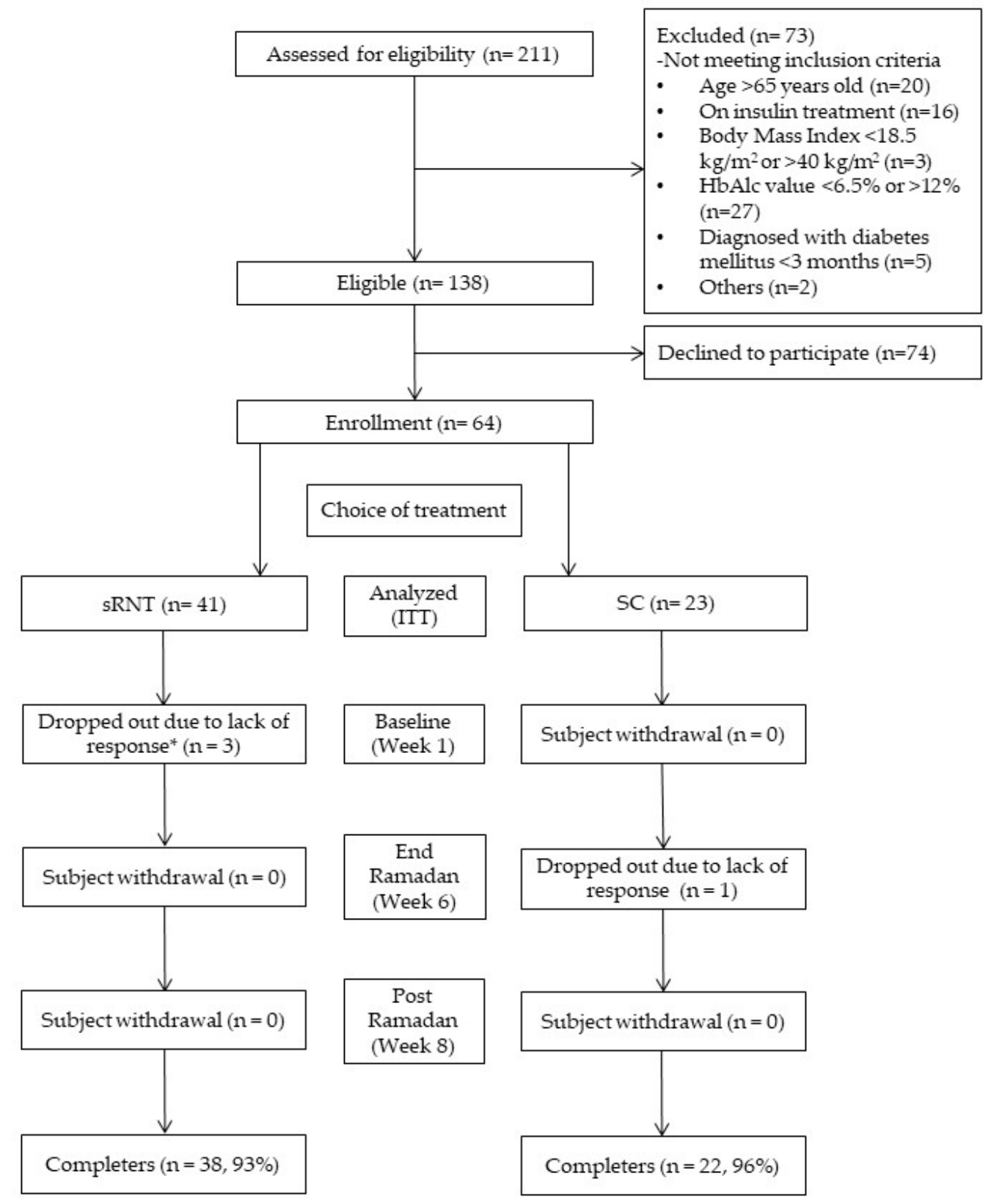

Figure 2. Screening and recruitment, * Three participants in structured Ramadan nutrition therapy, (sRNT) declined to participate before receiving the education. ITT, intention-to-treat analysis. 
Both groups were comparable at baseline (Table 2). The study included 31 men and 33 women with a mean age of $48.3 \pm 9.4$ years. At baseline, study participants had a mean $\mathrm{HbA} 1 \mathrm{c}$ of $8.0 \pm 1.5 \%$ and mean diabetes duration of $5.2 \pm 4.1$ years (Table 2). Their initial BMI was $30.3 \pm 5.4 \mathrm{~kg} / \mathrm{m}^{2}$, with $87.5 \%$ of the participants being overweight or obese. Almost half $(48.4 \%)$ of the participants had previously met a dietician, but only a small proportion (17.2\%) had received specific Ramadan advice. During the previous Ramadan, a small number of participants experienced hypoglycemia, but the difference was not significant ( $n=4,9.8 \%$ in sRNT vs. $n=1,4.3 \%$ in SC, $p=0.312$ ). The sRNT group had more women $(58.5 \%)$, and the participants had a longer duration of diabetes $(6 \pm 4$. years), and more comorbidities $(0.9 \pm 0.8)$ than the participants in SC group. The sRNT participants $(47.5 \%)$ were mainly treated with a sulphonylurea, whereas the majority of SC participants (52.2\%) received metformin (Table 2).

Table 2. Baseline characteristics of the participants $(n=64)$.

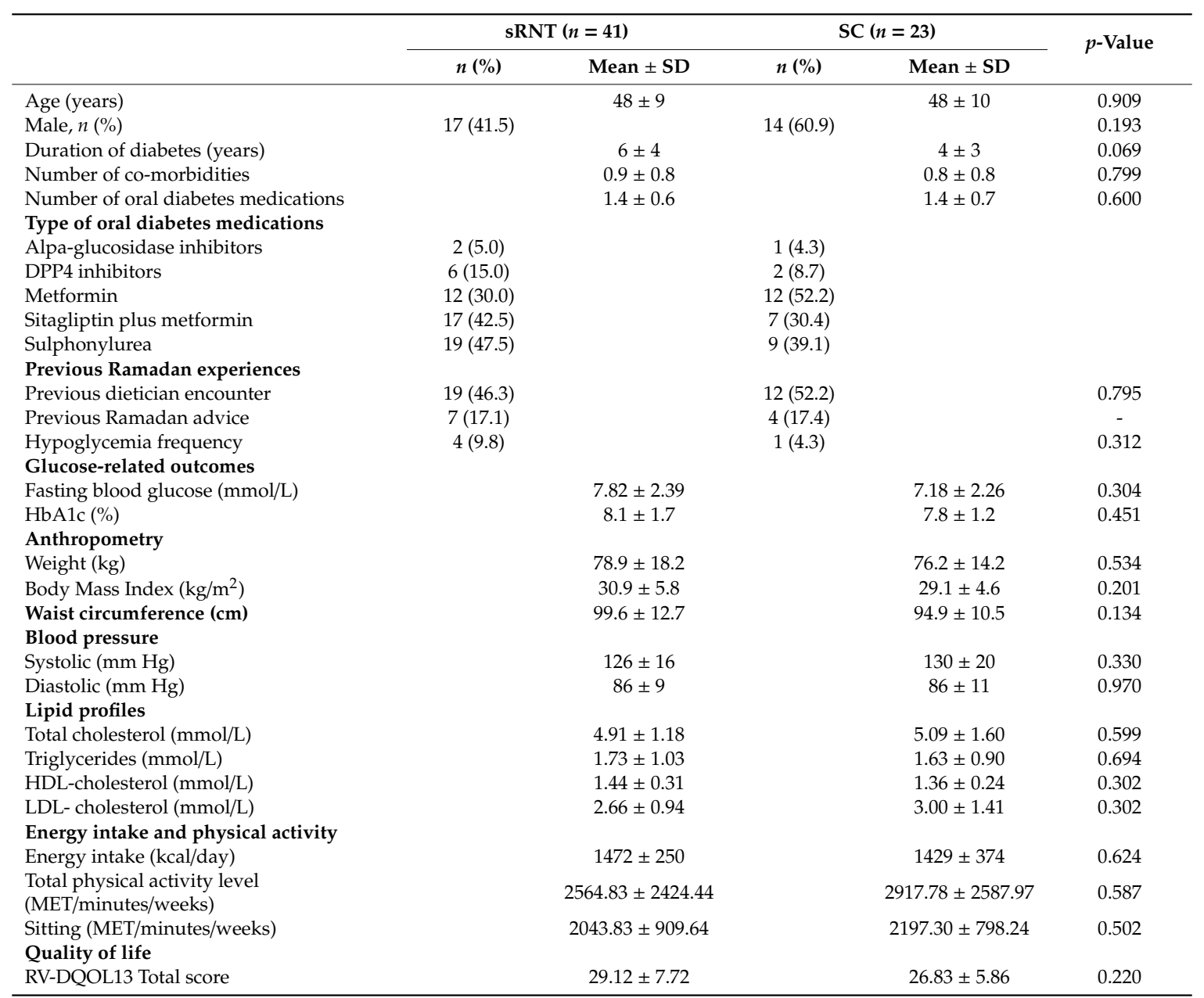

HbA1c, glycated hemoglobin; HDL, High-density lipoprotein; LDL, Low-density lipoprotein; sRNT: Structured Ramadan Nutrition Therapy; SU, Standard Care.

\subsection{Clinical Outcomes}

Participants in the sRNT group showed significantly bigger reduction in fasting blood glucose at end-Ramadan $(-1.47 \pm 0.30 \mathrm{mmol} / \mathrm{L}$ vs. $\quad-0.25 \pm 0.40 \mathrm{mmol} / \mathrm{L}, p<0.05)$ and post-Ramadan $(-0.90 \pm 0.32 \mathrm{mmol} / \mathrm{L}$ vs. $0.15 \pm 0.30 \mathrm{mmol} / \mathrm{L}, p<0.05)$ period than the participants in SC group. After 8 weeks, the HbA1c level decreased significantly in the sRN group $(-0.72 \pm 0.16 \%, p<0.001)$ but not in the SC group $(-0.35 \pm 0.24 \%, p=0.155)$; however, no difference was observed between the two groups. Similarly, BMI $\left(-0.64 \pm 0.11 \mathrm{~kg} / \mathrm{m}^{2}\right.$ vs. $\left.-0.60 \pm 0.11 \mathrm{~kg} / \mathrm{m}^{2}\right)$ and waist circumference $(-3.4 \pm 0.7 \mathrm{~cm}$ vs. $-2.5 \pm 0.8 \mathrm{~cm})$ decreased significantly over time in both groups, but the difference 
between the groups was not significant (Table 3). The level of triglycerides decreased significantly in sRNT group $(-0.21 \pm 0.08 \mathrm{mmol} / \mathrm{L}$ vs. $0.20 \pm 0.17 \mathrm{mmol} / \mathrm{L}, p<0.05)$ as compared to the SC group. HDL cholesterol $(0.2 \pm 0.0 \mathrm{mmol} / \mathrm{L}$ vs. $0.1 \pm 0.1 \mathrm{mmol} / \mathrm{L}$, $)$ increased in both groups whereas total cholesterol $(-0.1 \pm 0.2 \mathrm{mmol} / \mathrm{L}$ vs. $-0.2 \pm 0.2 \mathrm{mmol} / \mathrm{L})$ improved in the sRNT group $(p<0.001)$ which was not seen in SC group (Table 3).

\subsection{Dietary Intake and Quality of Life (QoL)}

Energy intake decreased in the sRNT group $(-118 \pm 50 \mathrm{kcal} /$ day, $p<0.001)$ and increased in the SC group $(20 \pm 103 \mathrm{kcal} /$ day, $p<0.05)$ (Table 3). Participants in the sRNT consumed less carbohydrate (\%TEI $-3.9 \% \pm 1.2 \%$ vs. $2.2 \% \pm 2.3 \%, p<0.05)$, more protein ( $\%$ TEI $0.9 \% \pm 0.7 \%$ vs. $-0.8 \% \pm 0.8 \%$, $p<0.05)$ and more fibre $(2.15 \pm 0.60 \mathrm{~g} /$ day vs. $0.60 \pm 0.87 \mathrm{~g} / \mathrm{day}, p<0.05)$. The rate of underreported energy intake was comparable between the two groups, with an average rate of $84.3 \%$ at baseline. We assessed the adherence rates to DSF within the sRNT group, which increased significantly throughout the study period. The adherence rate of incorporating the DSF at least once daily during Ramadan achieved $89.4 \pm 37.5 \%$. The scores for satisfaction $(-4.27 \pm 0.96$ vs. $-2.13 \pm 1.45)$ and QoL $(-4.81 \pm 1.55$ vs. $-0.74 \pm 1.31)$ improved significantly in $\operatorname{sNT}(p<0.001)$ group as compared to the SC group. The worry and impact domains were comparable between the two groups (Table 3 ). 
Table 3. Clinical outcomes, dietary intake, and quality of life throughout the study $(n=64)$.

\begin{tabular}{|c|c|c|c|c|c|c|c|c|}
\hline Variables & $n$ & Baseline & $\begin{array}{c}\text { End-Ramadan } \\
\text { Visit }\end{array}$ & $\begin{array}{c}\text { Post-Ramadan } \\
\text { Visit }\end{array}$ & $\begin{array}{c}\text { Within-Group } \\
p \text {-value }\end{array}$ & $\begin{array}{c}\text { Changes at } \\
\text { End-Ramadan } \\
\text { from Baseline }{ }^{\Delta}\end{array}$ & $\begin{array}{c}\text { Changes at Post } \\
\text { Ramadan from } \\
\text { Baseline }^{\Delta}\end{array}$ & $\begin{array}{c}\text { Interaction } \\
p \text {-Value }\end{array}$ \\
\hline Fasting blood glucose $(\mathrm{mmol} / \mathrm{L})$ & & & & & & & & 0.020 \\
\hline sRNT & 41 & $7.82 \pm 2.39$ & $6.35 \pm 1.64$ & $6.93 \pm 1.91$ & $<0.001$ & $-1.47 \pm 0.30$ * & $-0.90 \pm 0.32 *$ & \\
\hline SC & 23 & $7.18 \pm 2.26$ & $6.94 \pm 1.61$ & $7.34 \pm 1.44$ & 0.491 & $-0.25 \pm 0.40$ & $0.15 \pm 0.30$ & \\
\hline HbA1c (\%) & & & & & & & & 0.174 \\
\hline sRNT & 41 & $8.1 \pm 1.7$ & & $7.4 \pm 1.3$ & $<0.001$ & & $-0.72 \pm 0.16$ & \\
\hline SC & 23 & $7.8 \pm 1.2$ & Not measured & $7.4 \pm 1.2$ & 0.155 & Not measured & $-0.35 \pm 0.24$ & \\
\hline Weight (kg) & & & & & & & & 0.845 \\
\hline sRNT & 41 & $78.9 \pm 18.2$ & $76.9 \pm 18.0$ & $77.3 \pm 18.2$ & $<0.001$ & $-2.05 \pm 0.24$ & $-1.60 \pm 0.28$ & \\
\hline SC & 23 & $76.2 \pm 14.2$ & $74.3 \pm 13.9$ & $74.6 \pm 13.8$ & $<0.001$ & $-1.87 \pm 0.32$ & $-1.57 \pm 0.31$ & \\
\hline Body Mass Index $\left(\mathrm{kg} / \mathrm{m}^{2}\right)$ & & & & & & & & 0.772 \\
\hline SRNT & 41 & $30.9 \pm 5.8$ & $30.1 \pm 5.8$ & $30.3 \pm 5.8$ & $<0.001$ & $-0.80 \pm 0.10$ & $-0.64 \pm 0.11$ & \\
\hline SC & 23 & $29.1 \pm 4.6$ & $28.4 \pm 4.5$ & $28.5 \pm 4.4$ & $<0.001$ & $-0.71 \pm 0.12$ & $-0.60 \pm 0.11$ & \\
\hline Waist circumference $(\mathrm{cm})$ & & & & & & & & 0.604 \\
\hline sRNT & 41 & $99.6 \pm 12.7$ & $98.3 \pm 13.2$ & $96.2 \pm 13.1$ & $<0.001$ & $-1.33 \pm 0.63$ & $-3.40 \pm 0.65$ & \\
\hline SC & 23 & $94.9 \pm 10.5$ & $94.6 \pm 11.4$ & $92.4 \pm 11.0$ & 0.018 & $-0.30 \pm 0.94$ & $-2.47 \pm 0.84$ & \\
\hline Systolic blood pressure $(\mathrm{mmHg})$ & & & & & & & & 0.886 \\
\hline sRNT & 41 & $126 \pm 16$ & $121 \pm 14$ & $124 \pm 10$ & 0.140 & $-4.56 \pm 2.43$ & $-2.05 \pm 2.32$ & \\
\hline SC & 23 & $130 \pm 20$ & $126 \pm 15$ & $127 \pm 18$ & 0.229 & $-4.35 \pm 2.79$ & $-3.48 \pm 2.70$ & \\
\hline Diastolic blood pressure (mmHg) & & & & & & & & 0.885 \\
\hline sRNT & 41 & $86 \pm 9$ & $82 \pm 10$ & $84 \pm 10$ & 0.031 & $-3.49 \pm 1.20$ & $-1.02 \pm 1.31$ & \\
\hline $\mathrm{SC}$ & 23 & $86 \pm 11$ & $82 \pm 9$ & $84 \pm 10$ & 0.097 & $-3.70 \pm 1.46$ & $-2.04 \pm 1.89$ & \\
\hline Total cholesterol (mmol/L) & & & & & & & & 0.641 \\
\hline sRNT & 41 & $4.91 \pm 1.18$ & $4.35 \pm 0.96$ & $4.81 \pm 0.94$ & $<0.001$ & $-0.55 \pm 0.14$ & $-0.10 \pm 0.15$ & \\
\hline $\mathrm{SC}$ & 23 & $5.09 \pm 1.60$ & $4.64 \pm 1.31$ & $4.89 \pm 1.35$ & 0.135 & $-0.46 \pm 0.25$ & $-0.20 \pm 0.24$ & \\
\hline Triglycerides $(\mathrm{mmol} / \mathrm{L})$ & & & & & & & & 0.034 \\
\hline sRNT & 41 & $1.73 \pm 1.03$ & $1.32 \pm 0.57$ & $1.52 \pm 0.81$ & $<0.001$ & $-0.40 \pm 0.10$ & $-0.21 \pm 0.08 *$ & \\
\hline SC & 23 & $1.63 \pm 0.90$ & $1.59 \pm 1.24$ & $1.83 \pm 1.28$ & 0.296 & $-0.04 \pm 0.18$ & $0.20 \pm 0.17$ & \\
\hline HDL-cholesterol (mmol/L) & & & & & & & & 0.092 \\
\hline sRNT & 41 & $1.44 \pm 0.31$ & $1.34 \pm 0.25$ & $1.60 \pm 0.31$ & $<0.001$ & $-0.10 \pm 0.02$ & $0.16 \pm 0.03$ & \\
\hline SC & 23 & $1.36 \pm 0.24$ & $1.32 \pm 0.23$ & $1.46 \pm 0.32$ & 0.013 & $-0.05 \pm 0.04$ & $0.10 \pm 0.06$ & \\
\hline LDL-cholesterol (mmol/L) & & & & & & & & 0.481 \\
\hline sRNT & 40 & $2.66 \pm 0.94 \dagger$ & $2.44 \pm 0.96$ & $2.57 \pm 0.89$ & 0.093 & $-0.24 \pm 0.12$ & $-0.11 \pm 0.11$ & \\
\hline SC & 23 & $3.00 \pm 1.41$ & $2.54 \pm 0.97$ & $2.53 \pm 0.96$ & 0.174 & $-0.33 \pm 0.23$ & $-0.34 \pm 0.22$ & \\
\hline
\end{tabular}


Table 3. Cont.

\begin{tabular}{|c|c|c|c|c|c|c|c|c|}
\hline Variables & $n$ & Baseline & $\begin{array}{c}\text { End-Ramadan } \\
\text { Visit }\end{array}$ & $\begin{array}{c}\text { Post-Ramadan } \\
\text { Visit }\end{array}$ & $\begin{array}{c}\text { Within-Group } \\
p \text {-value }\end{array}$ & $\begin{array}{c}\text { Changes at } \\
\text { End-Ramadan } \\
\text { from Baseline }\end{array}$ & $\begin{array}{c}\text { Changes at Post } \\
\text { Ramadan from } \\
\text { Baseline }^{\Delta}\end{array}$ & $\begin{array}{c}\text { Interaction } \\
p \text {-Value }\end{array}$ \\
\hline \multicolumn{9}{|l|}{ Dietary intake } \\
\hline Energy intake (kcal/day) & & & & & & & & 0.347 \\
\hline sRNT & 41 & $1472 \pm 250$ & $1226 \pm 229$ & $1354 \pm 317$ & $<0.001$ & $-246 \pm 45$ & $-118 \pm 50$ & \\
\hline SC & 23 & $1429 \pm 374$ & $1234 \pm 280$ & $1449 \pm 375$ & 0.038 & $-195 \pm 90$ & $20 \pm 103$ & \\
\hline Carbohydrate (\%) & & & & & & & & 0.015 \\
\hline sRNT & 41 & $55 \pm 5$ & $53 \pm 6$ & $51 \pm 6$ & 0.003 & $-2.4 \pm 1.1^{*}$ & $-3.9 \pm 1.2 *$ & \\
\hline SC & 23 & $51 \pm 8$ & $53 \pm 7$ & $53 \pm 10$ & 0.460 & $2.4 \pm 2.0$ & $2.2 \pm 2.3$ & \\
\hline Protein $(\%)$ & & & & & & & & 0.026 \\
\hline sRNT & 41 & $15 \pm 3$ & $18 \pm 3$ & $16 \pm 4$ & 0.003 & $2.2 \pm 0.6^{*}$ & $0.9 \pm 0.7$ & \\
\hline $\mathrm{SC}$ & 23 & $16 \pm 3$ & $16 \pm 3$ & $16 \pm 3$ & 0.569 & $-0.5 \pm 0.8$ & $-0.8 \pm 0.8$ & \\
\hline Total fat $(\%)$ & & & & & & & & 0.163 \\
\hline sRNT & 41 & $30 \pm 5$ & $29 \pm 5$ & $32 \pm 5$ & 0.004 & $-0.5 \pm 0.9$ & $2.5 \pm 0.9$ & \\
\hline $\mathrm{SC}$ & 23 & $33 \pm 7$ & $31 \pm 5$ & $32 \pm 9$ & 0.571 & $-2.0 \pm 1.7$ & $-1.1 \pm 2.2$ & \\
\hline Total fiber intake (g/day) & & & & & & & & 0.014 \\
\hline sRNT & 41 & $5 \pm 2$ & $7 \pm 2$ & $7 \pm 4$ & $<0.001$ & $2.79 \pm 0.54$ & $2.15 \pm 0.60$ & \\
\hline SC & 23 & $4 \pm 3$ & $4 \pm 2$ & $5 \pm 3$ & 0.588 & $-0.01 \pm 0.72$ & $0.60 \pm 0.87$ & \\
\hline \multicolumn{9}{|l|}{ Quality of life } \\
\hline Satisfaction domain score & & & & & & & & 0.279 \\
\hline sRNT & 41 & $15.10 \pm 3.59$ & $11.24 \pm 3.88$ & $10.83 \pm 5.49$ & $<0.001$ & $-3.85 \pm 0.75$ & $-4.27 \pm 0.96$ & \\
\hline $\mathrm{SC}$ & 23 & $15.17 \pm 3.97$ & $13.26 \pm 4.11$ & $13.04 \pm 4.83$ & 0.199 & $-1.91 \pm 0.76$ & $-2.13 \pm 1.45$ & \\
\hline Impact domain score & & & & & & & & 0.113 \\
\hline sRNT & 41 & $7.27 \pm 3.75$ & $6.56 \pm 2.83$ & $6.90 \pm 2.78$ & 0.396 & $-0.71 \pm 0.57$ & $-0.37 \pm 0.66$ & \\
\hline $\mathrm{SC}$ & 23 & $5.78 \pm 1.62$ & $6.74 \pm 2.20$ & $6.83 \pm 2.06$ & 0.107 & $0.96 \pm 0.52$ & $1.04 \pm 0.57$ & \\
\hline Worry domain score & & & & & & & & 0.607 \\
\hline sRNT & 41 & $6.76 \pm 2.68$ & $6.41 \pm 2.72$ & $6.59 \pm 2.19$ & 0.665 & $-0.34 \pm 0.40$ & $-0.17 \pm 0.38$ & \\
\hline $\mathrm{SC}$ & 23 & $5.87 \pm 2.07$ & $5.96 \pm 1.64$ & $6.22 \pm 2.24$ & 0.466 & $0.09 \pm 0.21$ & $0.35 \pm 0.36$ & \\
\hline Total score & & & & & & & & 0.072 \\
\hline sRNT & 41 & $29.12 \pm 7.72$ & $24.22 \pm 6.83$ & $24.32 \pm 8.15$ & $<0.001$ & $-4.90 \pm 1.25 *$ & $-4.81 \pm 1.55$ & \\
\hline SC & 23 & $26.83 \pm 5.86$ & $25.96 \pm 6.62$ & $26.09 \pm 4.84$ & 0.749 & $-0.87 \pm 0.95$ & $-0.74 \pm 1.31$ & \\
\hline
\end{tabular}

Data are mean $\pm \mathrm{SD}^{*}$ Significant difference between the group, $p<0.05$, using Independent sample $\mathrm{t}$-test, ${ }^{\Delta}$ All data expressed as (mean $\pm \mathrm{SE}$ ) for absolute change in measures. HbA1c, glycated hemoglobin; HDL, High-density lipoprotein; LDL, Low-density lipoprotein; sRNT: Structured Ramadan Nutrition Therapy; SC, Standard Care. 


\subsection{Self-monitoring Blood Glucose Profiles}

Throughout Ramadan, participants in sRNT group had significantly better SMBG profiles at pre-dawn $(6.9 \mathrm{mmol} / \mathrm{L}$ vs. $7.8 \mathrm{mmol} / \mathrm{L}, p<0.05)$ and pre-bed $(7.6 \mathrm{mmol} / \mathrm{L}$ vs. $8.6 \mathrm{mmol} / \mathrm{L}, p<0.05)$ than the participants in SC group. After Ramadan, the SMBG profiles were consistently lower in participants of sRNT group than the SC group at each time point, but the difference was not significant (Figure 3).

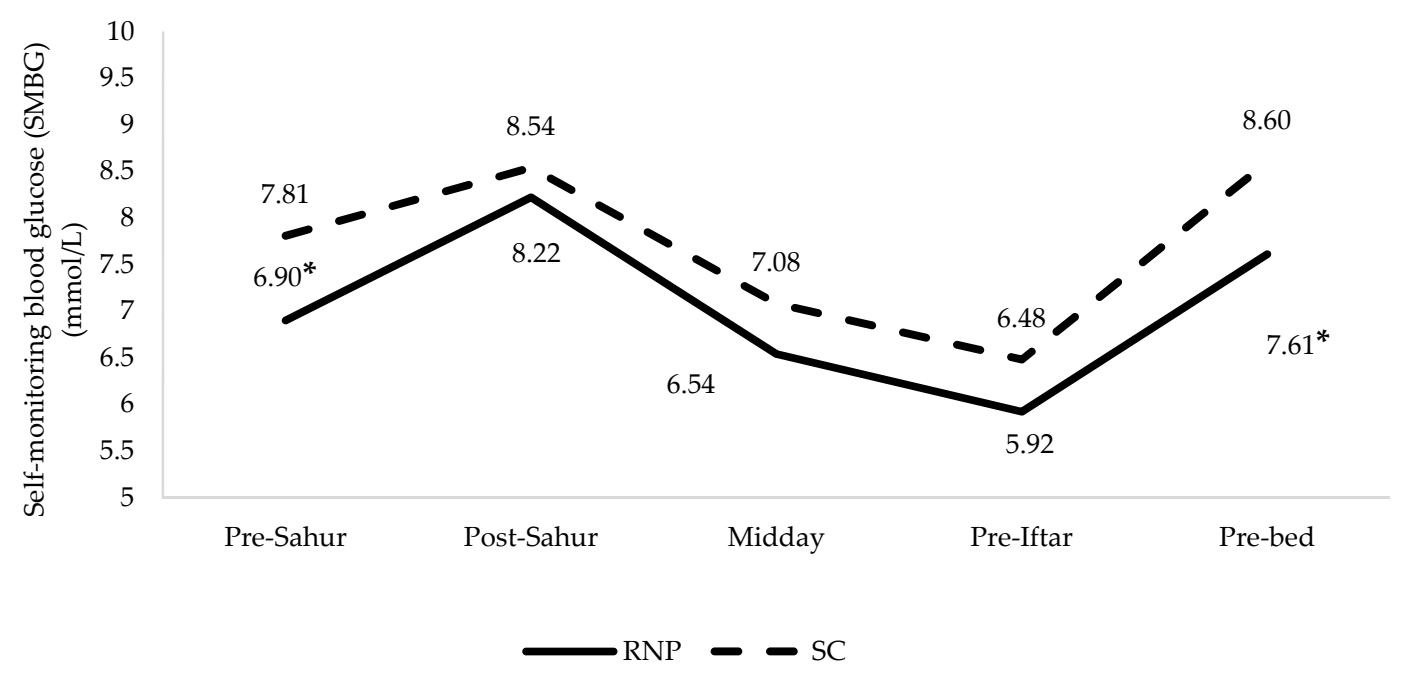

(a)

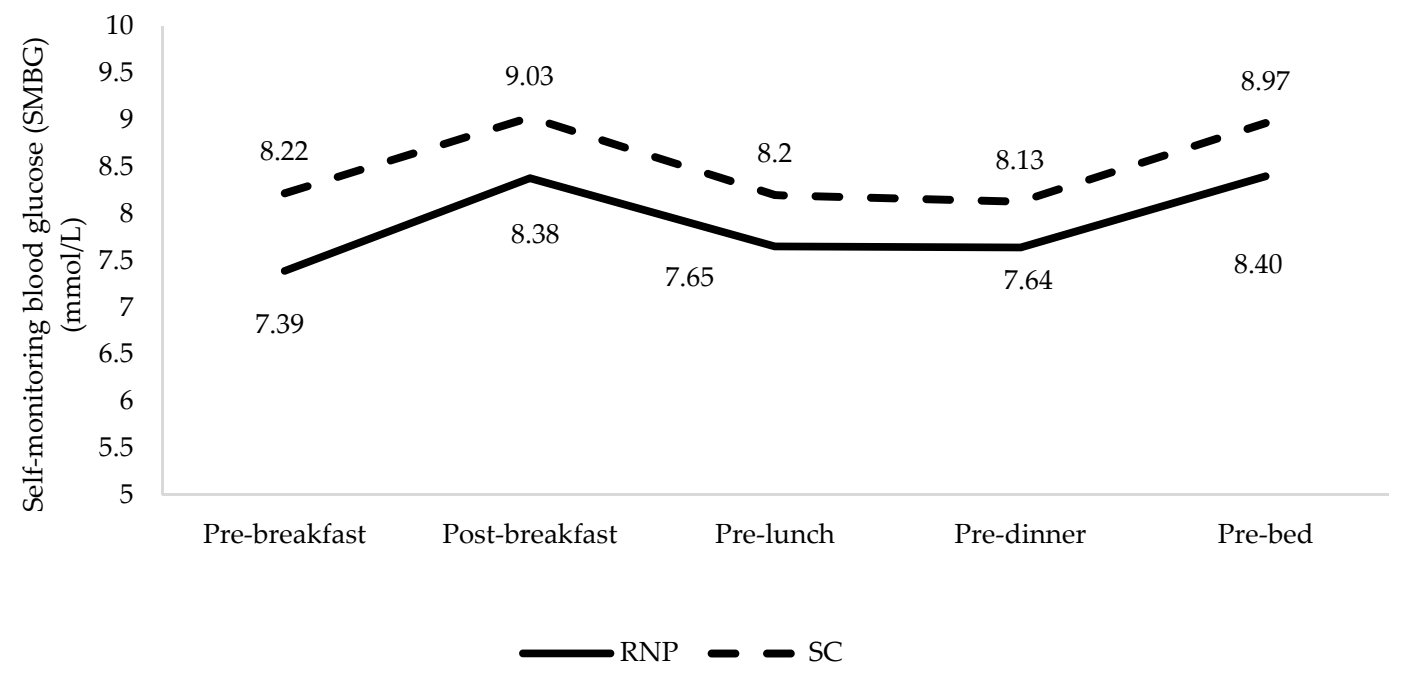

(b)

Figure 3. Self-monitoring blood glucose (SMBG) profiles between sRNT and SC, during. (a) Ramadan, (b) post-Ramadan, * Statistically significant differences between groups.

In total, 14 and 8 participants reported hypoglycemia during and after Ramadan, respectively, with $82 \%$ of them were on sulfonylurea medication. The majority of these participants were from the sRNT group $(n=11 ; 28.9 \%)$ vs. the SC group $(n=3 ; 13.6 \%)$, but the difference was not significant. The proportion of hypoglycemia improved after Ramadan in both groups but was still higher in sRNT $(n=6 ; 15.8 \%)$ than the SC $(n=2 ; 9.1 \%)$ group. However, the SC group experienced a significantly higher number of hypoglycemic episodes than those in the sRNT group both during (6.3 vs. 2.6, $p<0.05)$ and after Ramadan (3.0 vs. $1.3, p<0.05)$. At the end of the study, about $21.1 \%(n=8)$ of the 
participants in the sRNT and 9.1\% $(n=2)$ in the SC group reduced the dosage of diabetes medications, while one participant $(4.5 \%)$ from the SC group needed to increase the dosage of diabetes medications.

\subsection{Continuous Glucose Monitoring Profiles}

The baseline characteristics of participants who participated in the CGM study (sRNT =14, SC = 7) did not differ significantly from the whole study population. CGM participants $(n=21)$ and non-CGM participants $(n=43)$ were comparable in terms of age ( $49.3 \pm 10.0$ years vs. $47.8 \pm 9.2$ years), HbA1c level $(7.6 \pm 1.1 \%$ vs. $8.2 \pm 1.7 \%)$, duration of diabetes ( $5.2 \pm 4.1$ years vs. $5.2 \pm 4.1$ years) and BMI $\left(30.0 \pm 6.2 \mathrm{~kg} / \mathrm{m}^{2}\right.$ vs. $\left.30.4 \pm 5.1 \mathrm{~kg} / \mathrm{m}^{2}\right)$ (Table 4$)$.

The participants from sRNT group had better average sensor glucose $(6.85 \mathrm{mmol} / \mathrm{L} \mathrm{vs} .8 .30 \mathrm{mmol} / \mathrm{L}$, $p<0.05)$ and estimated $\mathrm{HbA} 1 \mathrm{c}$ level $(5.93 \%$ vs. $6.84 \%, p<0.05)$ than those from SC group (Table 3$)$. In addition, the participants from sRNT group spent significantly more time-in-target range $(82.32 \%$ vs. $61.7 \%, p<0.05)$ and spent less time-above-target range $(16.61 \%$ vs. $36.21 \%, p<0.05)$ than SC participants. No difference between the groups was observed for the time spent below-target-range (Table 4).

Table 4. Differences in continuous glucose monitoring reading during Ramadan. between sRNT and SC $(n=21)$.

\begin{tabular}{|c|c|c|c|c|}
\hline \multirow{2}{*}{ Variables } & \multicolumn{2}{|c|}{ Adjusted Mean $[95 \%$ CI] } & \multirow{2}{*}{$\begin{array}{c}\text { sRNT Versus SC } \\
\text { Adjusted Mean } \\
\text { Difference }[95 \% \mathrm{CI}]\end{array}$} & \multirow{2}{*}{$p$-Value } \\
\hline & sRNT $(n=14)$ & $\mathrm{SC}(n=7)$ & & \\
\hline Sensor glucose $(\mathrm{mmol} / \mathrm{L})$ & $\begin{array}{c}6.85 \\
{[6.05 ; 7.65]}\end{array}$ & $\begin{array}{c}8.30 \\
{[7.17 ; 9.43]}\end{array}$ & $\begin{array}{c}-1.45 \\
{[-2.84 ;-0.07]}\end{array}$ & 0.04 \\
\hline Estimated A1c (\%) & $\begin{array}{c}5.93 \\
{[5.44 ; 6.42]}\end{array}$ & $\begin{array}{c}6.84 \\
{[6.14 ; 7.54]}\end{array}$ & $\begin{array}{c}-0.91 \\
{[-1.76 ;-0.05]}\end{array}$ & 0.04 \\
\hline Time in range & & & & \\
\hline $\begin{array}{c}\text { Above range } \\
(>8.3 \mathrm{mmol} / \mathrm{L}(\%))\end{array}$ & $\begin{array}{c}16.61 \\
{[7.91 ; 25.31]}\end{array}$ & $\begin{array}{c}36.21 \\
{[23.87 ; 48.55]}\end{array}$ & $\begin{array}{c}-19.60 \\
{[-34.76 ;-4.44]}\end{array}$ & 0.01 \\
\hline $\begin{array}{c}\text { In target range } \\
(3.9-8.3 \mathrm{mmol} / \mathrm{L}(\%))\end{array}$ & $\begin{array}{c}82.32 \\
{[73.88 ; 90.76]}\end{array}$ & $\begin{array}{c}61.79 \\
{[49.83 ; 73.75]}\end{array}$ & $\begin{array}{c}20.53 \\
{[5.86 ; 35.19]}\end{array}$ & 0.01 \\
\hline $\begin{array}{c}\text { Below range } \\
(<3.9 \mathrm{mmol} / \mathrm{L}(\%))\end{array}$ & $\begin{array}{c}1.45 \\
{[0.34 ; 2.56]}\end{array}$ & $\begin{array}{c}1.52 \\
{[-0.06 ; 3.10]}\end{array}$ & $\begin{array}{c}-0.07 \\
{[-2.02 ; 1.88]}\end{array}$ & 0.94 \\
\hline
\end{tabular}

sRNT: Structured Ramadan Nutrition Therapy; SC, Standard Care.

\section{Discussion}

The current study proved the feasibility of providing structured NT with incorporated DSF despite the fasting and feasting nature of Ramadan. Ramadan is time-sensitive, which limits the ability to comply with dietary changes in a short period [27]. Hence, patients' preferences and choices are essential in optimizing dietary adherence. Although the randomized design eliminates selection bias [28], the random allocation may not match patients' preference primarily related to DSF consumption, thereby compromising study validity. Indeed, the current study mimics real-life clinical experience where patients opt for their treatment choice.

In this study, the number of participants in the sRNT and SC is markedly different, as more than half $(63 \%)$ preferred to use the sRNT regimen, and 37\% continued the standard nutrition care. The characteristics of the participants in both groups did not differ statistically. Still, the sRNT group had more women, longer duration of T2D, more comorbidities, and higher HbA1c levels than the participants in the SC group. It is understood that patients with long-standing T2D and more inadequate glycemic control tended to seek medical help and were willing to explore different treatment choices, which was particularly evident among women [29]. It is notable that women experienced a higher rate of hunger than men in early Ramadan but becoming less severe as Ramadan progresses [30]. Indeed, the hunger rating was comparable between men and women towards the end of Ramadan [30], suggesting a minimal effect of sex on the study outcomes. 
The fasting and feasting nature of Ramadan may cause a reduction in the adherence to DSF. Nonetheless, the present study achieved a good adherence rate of nearly $90 \%$ to DSF consumption during Ramadan, similar to the rate reported in another study using DSF in the non-Ramadan period [7]. This result indicates the feasibility of providing DSF as a part of the structured NT during Ramadan. Notably, the sRNT regimen was different from the other Ramadan-focused nutrition plans that did not include DSF in their intervention $[11,12,14]$. The incorporation of DSF in the sRNT was also different from other structured NT performed during the non-Ramadan period. In those studies, the DSF was used as a partial meal replacement for 1-2 meals/day to replace the usual meal [7-9]. In this study, DSF was consumed as part of the Suhoor and/or snack, together with other healthier meals within the prescribed carbohydrate and caloric limits.

Although the DSF was consumed with other healthy meals, it did not influence energy intake as the energy reduction was similar in both groups. Participants in sRNT group consumed more \%TEI protein and fiber but less \%TEI carbohydrates than the SC group, suggestive of the improvement in fasting blood glucose and triglycerides levels observed in this study. The improvement may be attributed to the macronutrient composition provided within the structured NT [9]. The DSF used in the study has distinctive characteristics as it comprises of low GI carbohydrates, rich in fiber, and high in whey protein [31]. In acute studies, the DSF produced lower postprandial glucose levels than breakfast cereals [31] or oats [32], which may explain the greater reduction in SMBG levels observed at pre-dawn and pre-bed times in the sRNT group as compared to the SC group. Additionally, participants of sRNT group had better CGM outcomes than the SC group. Although the CGM was not conducted in the entire study population, participants in sRNT spent almost $82 \%$ more time-in-target range, while it is recommended to spend 70\% more time in glucose target range among people with diabetes [23]. Spending more time in glucose target range is critically needed as it reduces the progression to retinopathy, delays microalbuminuria development, and improves HbA1c levels [23]. The results are intriguing and strongly calls for replicating the study with bigger sample size.

The sRNT regimen resulted in a clinically significant glycemic reduction in patients with T2D. The incremental benefits are similar to those reported in the studies using structured NT delivered during the non-Ramadan period [7-9]. Although the reduction in HbA1c by $0.72 \%$ in sRNT group was not significantly different from the SC group $(-0.35 \%)$, it was much higher than previously reported by Ramadan-focused education studies, where it ranged from $0.2 \%-0.4 \%$ among patients with T2D [10-14]. The improvement in HbA1c was unlikely due to medication or weight loss as both parameters remained unchanged throughout Ramadan. The improvement in glycemic parameters may have inadvertently caused a higher proportion of hypoglycemia in sRNT group. More participants in sRNT were taking sulphonylurea medications, whereas participants in SC received mainly metformin. It comes as no surprise that more participants in sRNT had hypoglycemia, owing to the nature of sulphonylureas that commonly causes hypoglycemia, especially during Ramadan [33]. No medication adjustment was made in either group prior to their enrollment in the study. Sulphonylureas may also induce weight gain [33], but we did not observe any significant difference regarding weight changes between the two groups.

The incidence of hypoglycemia is often associated with reduced QoL and increased fear of experiencing another hypoglycemic episode, which acts as a barrier for adherence to adequate treatment [34]. Despite a higher proportion of hypoglycemia in sRNT group, QoL and satisfaction with the treatment improved significantly, but this was not observed in SC patients. Compared to the usual care, a structured NT during Ramadan significantly reduced the number of hypoglycemic episodes, leading to more participants requiring a dosage reduction of diabetes medications in the sRN than the SC group at the end of the study period.

This study has some limitations. First, the patient preference design limits the ability to identify real differences between the groups, which is usually obtained in randomized controlled trials. However, the random allocation may not accord with patients' preferences of nutrition therapy, especially related to the use of DSF during Ramadan, thereby compromising study validity. Understanding patients' 
preferences replicate real-life routine practice, where the patients are given a choice of treatment. Second, this is a feasibility study, and it was not powered adequately. Nonetheless, we managed to detect significant benefits in clinical outcomes. Third, the high prevalence of underreported energy intake is a common issue as in other nutrition intervention studies, and it would have affected both the groups to the same extent. Lastly, the optimum repeat testing interval of 12 weeks is typically suggested for $\mathrm{HbA1c}$, but the evidence supporting this recommendation is only based on expert opinion and studies with small sample size, including 9-10 patients [35,36]. Hirst et al. [37] demonstrated that 8 weeks' change in $\mathrm{HbA1c}$ level following medication adjustments was reliable and robust in predicting the $\mathrm{HbA1c}$ change at 12 weeks [37], thereby suggesting that the 8-weeks duration may be sufficient to detect changes in HbA1c levels in our Ramadan study. The reduction in HbA1c at 8-weeks was also evident when using structured nutrition therapy in T2D and remained significant at 16-weeks [9]. Although Mottalib et al. [9] did not perform the study during Ramadan fasting, the results imply the potential of detecting changes in $\mathrm{HbA1c}$ up to 16 weeks following structured NT after Ramadan.

\section{Conclusions}

The structured NT for Ramadan may be a feasible and beneficial program for T2D patients observing Ramadan fasting as it showed an improvement in some components of clinical outcomes and QoL. However, the adjustment in medications is required, especially for those receiving insulin secretagogues such as sulphonylureas, prior to adopting the structured NT that incorporated DSF. These results support the need for future clinical trials with adequate power and considering other parameters that might affect fasting metabolism, such as sleeping patterns.

Supplementary Materials: The following are available online at http://www.mdpi.com/2072-6643/12/3/813/s1, Table S1: Energy intake recommendation and carbohydrate exchange distribution during Ramadan, Table S2: Daily energy intake distribution during Ramadan, Table S3: Sample menu for one day, Table S4: Ramadan nutrition plate composition.

Author Contributions: Conceptualization, B.-N.M.Y., W.Z.H.H.W.Z., and O.H.; Formal analysis, B.-N.M.Y., N.F.Y., A.S.M.S., and F.Y.H.; Funding acquisition, B.-N.M.Y.; Investigation, B.-N.M.Y., N.F.Y., A.S.M.S., and F.Y.H.; Methodology, B.-N.M.Y., W.Z.H.H.W.Z., and O.H.; Supervision, B.-N.M.Y.; Writing—original draft, B.-N.M.Y.; Writing—review and editing, B.-N.M.Y., W.Z.H.H.W.Z., Z.A.Z., N.O., F.M., N.F.Y., A.S.M.S., F.Y.H., R.L.X.Y., and A.M. All authors have read and agreed to the published version of the manuscript.

Funding: This research was funded by Nestlé Health Science, Grant number: 6300214 and Fundamental Research Grant Scheme by the Ministry of Higher Education Malaysia (FRGS/1/2018/SKK05/UPM/02/2, grant number: 5540099).

Acknowledgments: This study was funded by Nestlé Health Science (Grant number: 6300214) and Fundamental Research Grant Scheme by the Ministry of Higher Education Malaysia (FRGS/1/2018/SKK05/UPM/02/2, grant number: 5540099). However, Nestlé Health Science had no role in the design of the study, in the collection and interpretation of data, and in the decision to publish the results. Part of the data from this study were presented at International Diabetes Federation Congress 2019. The authors would like to extend their gratitude to the participants of the study, and the staff at the University Health Centre, Universiti Putra Malaysia (UPM), Malaysia for their support and collaboration throughout the data collection period.

Conflicts of Interest: All authors have no financial interests to declare.

\section{References}

1. Hassanein, M.M.; Al-Arouj, M.; Hamdy, O.; Bebakar, W.M.W.; Jabbar, A.; Al-Madani, A.; Hanif, W.; Lessan, N.; Basit, A.; Tayeb, K.; et al. Diabetes and Ramadan: Practical guidelines. Diabetes Res. Clin. Pract. 2017, 126, 303-316. [CrossRef]

2. Al-Arouj, M.; Assaad-Khalil, S.; Buse, J.B.; Fahdil, I.; Fahmy, M.; Hafez, S.; Hassanein, M.; Ibrahim, M.; Kendall, D.; Kishawi, S.; et al. Recommendations for Management of Diabetes During Ramadan. Diabetes Care 2010, 33, 1895-1902. [CrossRef]

3. Jabbar, A.; Hassanein, M.M.; Beshyah, S.A.; Boye, K.S.; Yu, M.; Babineaux, S.M. CREED study: Hypoglycaemia during Ramadan in individuals with Type 2 diabetes mellitus from three continents. Diabetes Res. Clin. Pract. 2017, 132, 19-26. [CrossRef] 
4. Bravis, V.; Hui, E.; Salih, S.; Mehar, S.; Hassanein, M.; Devendra, D. Ramadan Education and Awareness in Diabetes (READ) programme for Muslims with Type 2 diabetes who fast during Ramadan. Diabet. Med. 2010, 27, 327-331. [CrossRef]

5. Yarahmadi, S.; Larijani, B.; Bastanhagh, M.H.; Pajouhi, M.; Jalili, R.B.; Zahedi, F.; Zendehdel, K.; Akrami, S.M. Metabolic and clinical effects of Ramadan fasting in patients with type II diabetes. JCPSP 2003, 13, 329-332.

6. International Diabetes Federation and the DAR International Alliance. Diabetes and Ramadan: Practical Guidelines; International Diabetes Federation: Brussels, Belgium, 2016.

7. Chee, W.; Singh, H.K.G.; Hamdy, O.; Mechanick, J.I.; Lee, V.K.M.; Barua, A.; Ali, S.Z.M.; Hussein, Z. Structured lifestyle intervention based on a trans-cultural diabetes-specific nutrition algorithm (tDNA) in individuals with type 2 diabetes: A randomized controlled trial. BMJ Open Diabetes Res. Care 2017, 5, e000384. [CrossRef] [PubMed]

8. The Look AHEAD Study: A Description of the Lifestyle Intervention and the Evidence Supporting It*. Obes. 2006, 14, 737-752. [CrossRef] [PubMed]

9. Mottalib, A.; Abrahamson, M.J.; Pober, D.M.; Polak, R.; Eldib, A.; Tomah, S.; Ashrafzadeh, S.; Hamdy, O. Effect of diabetes-specific nutrition formulas on satiety and hunger hormones in patients with type 2 diabetes. Nutr. Diabetes 2019, 9, 1-6. [CrossRef] [PubMed]

10. Hassanein, M.M.; Abdelgadir, E.; Bashier, A.; Rashid, F.; Al Saeed, M.; Khalifa, A.; Eltayb, F.; Abuelkheir, S.; Abdellatif, M.; Sayyah, F.; et al. The role of optimum diabetes care in form of Ramadan focused diabetes education, flash glucose monitoring system and pre-Ramadan dose adjustments in the safety of Ramadan fasting in high risk patients with diabetes. Diabetes Res. Clin. Pract. 2019, 150, 288-295. [CrossRef] [PubMed]

11. Alawadi, F.; Rashid, F.; Bashier, A.; Abdelgadir, E.; Al Saeed, M.; Abuelkheir, S.; Khalifa, A.; Al Sayyah, F.; Bachet, F.; Elsayed, M.; et al. The use of Free Style Libre Continues Glucose Monitoring (FSL-CGM) to monitor the impact of Ramadan fasting on glycemic changes and kidney function in high-risk patients with diabetes and chronic kidney disease stage 3 under optimal diabetes care. Diabetes Res. Clin. Pract. 2019, 151, 305-312. [CrossRef] [PubMed]

12. Bashier, A.; Khalifa, A.; Al Awadi, F.F.; Alsayyah, F.; Al Saeed, M.; Rashid, F.; Abdelgadir, E.; Bachet, F.; Abuelkheir, S.; Elsayed, M.; et al. Impact of optimum diabetes care on the safety of fasting in Ramadan in adult patients with type 2 diabetes mellitus on insulin therapy. Diabetes Res. Clin. Pract. 2019, 150, 301-307. [CrossRef] [PubMed]

13. Abdelgadir, E.; Rashid, F.; Bashier, A.; Al Saeed, M.; Khalifa, A.; Al Awadi, F.F.; Hassanein, M. Use of flash glucose monitoring system in assessing safety of the SGLT2 inhibitors during Ramadan fasting in high risk insulin treated patients with type 2 diabetes. Diabetes Metab. Syndr. Clin. Res. Rev. 2019, 13, 2927-2932. [CrossRef] [PubMed]

14. El Toony, L.F.; Hamad, D.A.; Omar, O.M. Outcome of focused pre-Ramadan education on metabolic and glycaemic parameters in patients with type 2 diabetes mellitus. Diabetes Metab. Syndr. Clin. Res. Rev. 2018, 12, 761-767. [CrossRef] [PubMed]

15. The Zimbabwe Hand Jive: A Simple Method of Portion Control. Available online: https://www.umassmed. edu/dcoe/diabetes-education/nutrition/zimbabwe-hand-jive/ (accessed on 2 December 2019).

16. Imai, S.; Matsuda, M.; Hasegawa, G.; Fukui, M.; Obayashi, H.; Ozasa, N.; Kajiyama, S. A simple meal plan of 'eating vegetables before carbohydrate' was more effective for achieving glycemic control than an exchange-based meal plan in Japanese patients with type 2 diabetes. Asia Pac. J. Clin. Nutr. 2011, 20, 161. [PubMed]

17. Malaysian Dietitians' Association. Medical Nutrition Therapy Guidelines for Type 2 Diabetes Mellitus, 2nd ed.; Malaysian Dietitians' Association and Ministry of Health: Putrajaya, Malaysia, 2013.

18. Ministry of Health Malaysia. Campaign Quarter Quarter Half, Malaysian Healthy Plate; Nutrition Division, Ministry of Health: Putrajaya, Malaysia, 2017.

19. Willett, W. Nutritional Epidemiology, 3rd ed.; Oxford University Press: New York, NY, USA, 2013.

20. Mafauzy, M.; Mohammed, W.B.; Anum, M.Y.; Zulkifli, A.; Ruhani, A.H. A study of the fasting diabetic patients during the month of Ramadan. Med. J. Malays. 1990, 45, 14-17.

21. Goldberg, G.R.; Black, A.E.; Jebb, S.A.; Cole, T.J.; Murgatroyd, P.R.; Coward, W.A.; Prentice, A.M. Critical evaluation of energy intake data using fundamental principles of energy physiology: 1 . Derivation of cut-off limits to identify under-recording. Eur. J. Clin. Nutr. 1991, 45, 569-581. 
22. Bujang, M.A.; Ismail, M.; Hatta, N.K.; Othman, S.H.; Baharum, N.; Lazim, S.S. Validation of the Malay version of Diabetes Quality of Life (DQOL) questionnaire for adult population with type 2 diabetes mellitus. Malays. J. Med. Sci. 2017, 24, 86-96. [CrossRef]

23. Battelino, T.; Danne, T.; Bergenstal, R.M.; Amiel, S.A.; Beck, R.; Biester, T.; Bosi, E.; Buckingham, B.A.; Cefalu, W.T.; Close, K.L.; et al. Clinical Targets for Continuous Glucose Monitoring Data Interpretation: Recommendations from the International Consensus on Time in Range. Diabetes Care 2019, 42, 1593-1603. [CrossRef]

24. Lee, J.Y.; Wong, C.P.; Tan, C.S.S.; Nasir, N.H.; Lee, S.W.H. Telemonitoring in fasting individuals with Type 2 Diabetes Mellitus during Ramadan: A prospective, randomised controlled study. Sci. Rep. 2017, 7, 10119. [CrossRef]

25. Billingham, S.A.; Whitehead, A.L.; Julious, S.A. An audit of sample sizes for pilot and feasibility trials being undertaken in the United Kingdom registered in the United Kingdom Clinical Research Network database. BMC Med. Res. Methodol. 2013, 13, 104. [CrossRef]

26. Montori, V.M.; Guyatt, G.H. Intention-to-treat principle. CMAJ 2001, 165, 1339-1341. [PubMed]

27. Vasan, S.K.; Karol, R.; Mahendri, N.V.; Arulappan, N.; Jacob, J.J.; Thomas, N. A prospective assessment of dietary patterns in Muslim subjects with type 2 diabetes who undertake fasting during Ramadan. Indian J. Endocrinol. Metab. 2012, 16, 552-557. [PubMed]

28. Sil, A.; Kumar, P.; Kumar, R.; Das, N.K. Selection of control, randomization, blinding, and allocation concealment. Indian Dermatol. Online J. 2019, 10, 601-605. [PubMed]

29. Atwine, F.; Hultsjö, S.; Albin, B.; Hjelm, K. Health-care seeking behaviour and the use of traditional medicine among persons with type 2 diabetes in south-western Uganda: A study of focus group interviews. Pan Afr. Med. J. 2015, 20, 1-13. [CrossRef]

30. Finch, G.M.; Day, J.E.; Welch, D.A.; Rogers, P.J. Appetite changes under free-living conditions during Ramadan fasting. Appetite 1998, 31, 159-170. [CrossRef]

31. Gulati, S.; Misra, A.; Nanda, K.; Pandey, R.M.; Garg, V.; Ganguly, S.; Cheung, L. Efficacy and tolerance of a diabetes specific formula in patients with type 2 diabetes mellitus: An open label, randomized, crossover study. Diabetes Metab. Syndr. Clin. Res. Rev. 2015, 9, 252-257. [CrossRef]

32. Mottalib, A.; Mohd-Yusof, B.-N.; Shehabeldin, M.; Pober, D.M.; Mitri, J.; Hamdy, O. Impact of diabetes-specific nutritional formulas versus oatmeal on postprandial glucose, insulin, GLP-1 and postprandial lipidemia. Nutrients 2016, 8, 443. [CrossRef]

33. Ibrahim, M.; Al Magd, M.A.; Annabi, F.A.; Assaad-Khalil, S.; Ba-Essa, E.M.; Fahdil, I.; Karadeniz, S.; Meriden, T.; Misha'L, A.A.; Pozzilli, P.; et al. Recommendations for management of diabetes during Ramadan: Update 2015. BMJ Open Diabetes Res. Care 2015, 3, e000108. [CrossRef]

34. Green, A.J.; Fox, K.M.; Grandy, S. Self-reported hypoglycemia and impact on quality of life and depression among adults with type 2 diabetes mellitus. Diabetes Res. Clin. Pract. 2012, 96, 313-318. [CrossRef]

35. Tahara, Y.; Shima, K. The response of GHb to stepwise plasma glucose change over time in diabetic patients. Diabetes Care 1993, 16, 1313-1314. [CrossRef]

36. Tahara, Y.; Shima, K. Kinetics of $\mathrm{HbA1c}$, glycated albumin, and fructosamine and analysis of their weight functions against preceding plasma glucose level. Diabetes Care 1995, 18, 440-447. [CrossRef] [PubMed]

37. Hirst, J.A.; Stevens, R.J.; Farmer, A.J. Changes in HbA1c level over a 12-week follow-up in patients with type 2 diabetes following a medication change. PLoS ONE 2014, 9, 1-7. [CrossRef] [PubMed]

(C) 2020 by the authors. Licensee MDPI, Basel, Switzerland. This article is an open access article distributed under the terms and conditions of the Creative Commons Attribution (CC BY) license (http://creativecommons.org/licenses/by/4.0/). 